\title{
Numerical investigation of mixed convection boundary layer flow for nanofluids under quasilinearization technique
}

\author{
Srimanta Maji ${ }^{1} \cdot$ Akshaya K. Sahu $^{1}$ \\ Received: 20 May 2021 / Accepted: 16 September 2021 \\ Published online: 09 October 2021 \\ (c) The Author(s) $2021 \quad$ OPEN
}

\begin{abstract}
The study of boundary layer flow under mixed convection has been investigated numerically for various nanofluids over a semi-infinite flat plate which has been placed vertically upward for both buoyancy-induced assisting and buoyancyinduced opposing flow cases. To facilitate numerical calculations, a suitable transformation has been made for the governing partial differential equations (PDEs). Then, similarity method has been applied locally to approximate the nonlinear PDEs into a coupled nonlinear ordinary differential equations (ODEs). Then, quasilinearization method has been taken for linearizing the nonlinear terms which are present in the governing equations. Thereafter, implicit trapezoidal rule has been taken for integration numerically along with principle of superposition. The effect of physical parameters which are involved in the study are analyzed on the flow and heat transfer characteristics. This study reveals the presence of dual solutions in case of opposing flow. Further, this study shows that with increasing $\phi$ and $\operatorname{Pr}$, the range of existence of dual solutions becomes wider. Also, it has been noted that nanofluids enhance the process of heat transfer for buoyancy assisting flow and it delays the separation point in case of opposing flow.
\end{abstract}

Keywords Mixed convection · Dual solutions · Nanofluids · Quasilinearization method

\section{Introduction}

Boundary layer flow under mixed convection with heated or cooled surface is a topic of synchronous studies in fluid and thermal sciences. Therefore, to understand the transport phenomena, the study on boundary layer flow is an important concept. There are considerable amount of research works ([1-5, 8] and so on) have been found on the classical theory of boundary layer flow under mixed convection. Merkin [1] studied the boundary layer problem for both buoyancy-induced assisting and opposing flow under mixed convection over a vertical plate. Probably he was the first who gave the idea of flow separation for buoyancy opposing case and Wilks and Bramley [5] first observed the presence of dual solutions for mixed convection buoyancy-induced opposing flow. Then, Merkin [6] also found the dual solutions in a porous medium. Ishak et al. [7] extended the work of Wilks and Bramley for a vertical permeable plate. Thereafter, many investigators (Mahmood and Merkin [8], Ramachandran et al. [9], Ridha [10], Weidman et al. [11], Xu and Liao [12], Ishak et al. [13], Afzal et al. [14]) noticed the presence of dual solutions for different types of boundary layer flow problems.

The common heat transfer fluids are not much effective as expected for the enhancement in heat transfer process for their lower thermal conductivity. With the pioneer invention of "nanofluid" which is a combination of nanosize particle and a heat transfer fluid, invented by Choi [15] in the year 1995, the study on nanofluids has attracted the attention of researchers for their higher thermal

Srimanta Maji, maji.srimanta758@gmail.com | 'Department of Mathematics, Institute of Chemical Technology, Mumbai, Maharashtra 400019, India.

SN Applied Sciences ～～～～（2021) 3:833 $\quad$ https://doi.org/10.1007/s42452-021-04811-1 
conductivities. In many thermal applications, it has been used potentially. The field of applications of nanofluids are energy storage [16], microbial fuel cell [17], space and defense [18], nuclear reactors cooling [19], heating buildings and reducing pollution [20], industrial cooling [21], nano-drug delivery [22], friction reduction [23], solar absorption [24] and so on.

A review on heat transfer enhancement for nanofluids has been published by Wang and Mujumdar [25], Das et al. [26], and a comprehensive study on heat transfer under convection has been made by Buongiorno [27] in order to analyze the enhancement in heat transfer for nanofluids. It can be inferred that only very few studies have been made for finding dual solutions for nanofluids in case of opposing flow over a flat plate. Bachok et al. [28] were probably the first who observed the presence of dual solutions in their numerical simulation for a vertical plate which was moving in the opposite directions of free stream velocity for a steady-state boundary layer flow problem for nanofluids. However, the effect of $\phi$ was not clearly mentioned on the heat transfer. Rana and Bhargava [29] studied the effect of $\phi$ for various nanofluids on boundary layer flow problem with heated source/sink over a vertical plate which was temperature dependent. They observed that the cooling performance for the vertical plate was highest for the nanofluid having nanoparticle with higher thermal conductivity. However, they did not report about the dual solutions. The boundary layer flow under mixed convection for nanofluid past a thin vertical cylinder was studied by Grosan and Pop [30] by considering the flow as axisymmetric. They observed that the enhancement in heat transfer was also a function of particle concentration and with the changes in small volume fraction of nanoparticles, significant changes had been observed for Nusselt number and skin friction coefficient. Also, they showed that in case of buoyancy opposing flow dual solutions were found. Zaimi et al. [31] showed the presence of dual solutions for the cases of shrinking and stretching in their study of heat transfer past a nonlinear permeable stretching and shrinking sheet. In case of suction, they noticed that the range for dual solutions became wider and temperature reduction was much faster with the increase in particle concentration in nanofluids for a particular range of stretching/shrinking parameter. Patrulescu et al. [32] found the possible range of dual solutions in case of opposing flow when they studied boundary layer flow problem under the mixed convection for nanofluids on a vertical impermeable frustum of a cone. The boundary layer flow under the effects of magneto-hydrodynamic (MHD) through a permeable wedge was studied by Xu et al. [33]. They pointed out that the dual solutions were existed for negative pressure gradient and also observed the small variation in viscosity. Flow separation was delayed in case of suction. In most of the aforementioned works on nanofluids, the researchers have taken Prandlt number (Pr) for small range $(0.7-10)$ in their studies. Due to its highly nonlinearity, the differential equations behave as stiff differential equations for higher Pr. The stiffness can be removed by applying suitable implicit method.

Thus, in the present work, a numerical investigation has been made for boundary layer flow under mixed convection for different nanofluids over a flat plate which has been placed vertically and also both the buoyancyinduced assisting and opposing flow cases are considered in the present work. The main aim of the study is to obtain dual solutions by using an efficient numerical method and then to study the effects of various nanofluids for different parameters on the enhancement of heat transfer. For numerical simulation, an implicit trapezoidal method has been incorporated for numerical integration along with quasilinearization method to overcome the stiffness of higher Pr. Quasilinearization method is a powerful technique to find the dual solutions from a set of nonlinear ODEs and for numerical integration trapezoidal method is a stable method. The detailed discussion on the numerical method has been discussed in the subsequent sections.

\subsection{Mathematical formulation}

In the present work, we consider an incompressible, twodimensional, steady-state laminar boundary layer flow under mixed convection for nanofluids over a flat plate which is directed vertically upward as shown in Fig. 1. With the following assumptions on nanofluids, (i) nanofluids are assumed to be Newtonian, (ii) size and shape of the nanoparticles are uniform and well dispersed in the base fluid, (iii) nanoparticles and base fluid are considered to be in thermal equilibrium.

By considering the Boussinesq approximation along with the assumptions, the governing equations for nanofluid can be written as [29]:

$$
\frac{\partial u}{\partial x}+\frac{\partial v}{\partial y}=0
$$

$$
\begin{aligned}
& u \frac{\partial u}{\partial x}+v \frac{\partial v}{\partial y}=\frac{\mu_{n f}}{\rho_{n f}} \frac{\partial^{2} u}{\partial y^{2}}+\frac{\rho_{s} \beta_{s}+(1-\phi) \rho_{f} \beta_{f}}{\rho_{n f}} g\left(T-T_{\infty}\right) \\
& u \frac{\partial T}{\partial x}+v \frac{\partial T}{\partial y}=\alpha_{n f} \frac{\partial^{2} T}{\partial y^{2}}
\end{aligned}
$$


and the boundary conditions along with the

$u(x, 0)=0, v(x, 0)=0, u(x, \infty)=U_{\infty}, T(x, 0)=T_{w}$ and $T(x, \infty)=T_{\infty}$

where $x$ and $y$ are along and perpendicular to the semiinfinite vertical flat plate, respectively. $u$ and $v$ are the velocities along $x$ and $y$ directions. $U_{\infty}$ represents the free stream velocity. Further, viscosity, density, thermal diffusivity, thermal conductivity, and specific heat for nanofluids are given as follows [34]:

$\mu_{n f}=\frac{\mu_{f}}{(1-\phi)^{2.5}}$

$\rho_{n f}=(1-\phi) \rho_{f}+\phi \rho_{s}$

$\alpha_{n f}=\frac{k_{n f}}{\left(\rho C_{p}\right)_{n f}}$

$\frac{k_{n f}}{k_{f}}=\frac{\left(k_{s}+2 k_{f}\right)-2 \phi\left(k_{f}-k_{s}\right)}{\left(k_{s}+2 k_{f}\right)+\phi\left(k_{f}-k_{s}\right)}$

$\left(\rho C_{p}\right)_{n f}=(1-\phi)\left(\rho C_{p}\right)_{f}+\phi\left(\rho C_{p}\right)_{s}$

In order to facilitate the numerical computations, equations (1)-(3) have been transformed into another co-ordinate system $(\xi, \eta)$ by using the relation as follows:

$\eta=y \sqrt{\frac{U_{\infty}}{v_{f} x}}, \xi=\frac{x}{L}$

along with the stream function and the non-dimensional temperature profile as given by

$\psi=\sqrt{U_{\infty} v_{f} x} f(\xi, \eta)$

and

$\theta(\xi, \eta)=\frac{T-T_{\infty}}{T_{w}-T_{\infty}}$

where the stream function $\psi$ is related to the variable $u$ and $v$ as $u=\frac{\partial \psi}{\partial y}$ and $v=-\frac{\partial \psi}{\partial x}$. Equations (1)-(3) with the above transformation reduce to $f(\xi, 0)=0, \theta(\xi, 0)=1, f^{\prime}(\xi, 0)=0, f^{\prime}(\xi, \infty)=1, \theta(\xi, \infty)=0$.

as boundary conditions. Here $\lambda=R_{i} \xi$, where $R_{i}=\frac{G r}{R e^{2}}$, the Richardson number, and $\operatorname{Pr}=\frac{v_{f}}{\alpha_{f}}$, the Prandtl number, where $G r=\frac{g \beta_{f}\left(T_{w}-T_{\infty}\right) L^{3}}{v_{f}^{2}}$, the Grashof number and $R e=\frac{U_{\infty} L}{v_{f}}$, the Reynolds number.

To solve the nonlinear coupled PDEs (6) and (7), similarity method has been used locally. In this method, the variations with respect to the variable $\xi$ are very small. Thus, equations (6) and (7) become

$$
\begin{aligned}
\left.\frac{1}{1-\phi+\phi \frac{\rho_{s}}{\rho_{f}}}\left[\frac{1}{(1-\phi)^{2.5}} f^{\prime \prime \prime}+\left((1-\phi)+\phi \frac{(\rho \beta)_{s}}{(\rho \beta)_{f}}\right)\right) \lambda \theta\right] \\
+\frac{1}{2} f f^{\prime \prime}=0
\end{aligned}
$$

$\frac{1}{(1-\phi)+\phi \frac{\left(\rho C_{p}\right)_{s}}{\left(\rho C_{p}\right)_{f}}}\left[\frac{1}{\operatorname{Pr}}\left(\frac{k_{n f}}{k_{s}}\right) \theta^{\prime \prime}\right]+\frac{1}{2} f \theta^{\prime}=0$

The physical quantities, the skin friction coefficient $C_{f}$, and the local Nusselt number $N u_{x}$ are defined as

$$
C_{f}=\frac{\tau_{w}}{\frac{1}{2} \rho_{n f} U_{\infty}^{2}}, N u_{x}=-\frac{q_{w} x}{k_{f}\left(T_{w}-T_{\infty}\right)}
$$

where the shear stress at the wall, $\tau_{w}=\mu_{n f}\left(\frac{\partial u}{\partial y}\right)_{y=0}$ and the heat flux from plate surface, $q_{w}=-k_{n f}\left(\frac{\partial T}{\partial y}\right)_{y=0}$. Thus, after simplification, reduced skin friction coefficient $\left(C_{f_{r d}}\right)$ and reduced local Nusselt number $\left(N u_{r d}\right)$ for nanofluids can be written as

$$
C_{f}[R e]^{0.5}=2 \frac{f^{\prime \prime}(\xi, 0)}{(1-\phi)^{2.5}}, \quad N u_{x}[R e]^{-0.5}=-\frac{k_{n f}}{k_{f}} \theta^{\prime}(\xi, 0)
$$

$\left.\frac{1}{1-\phi+\phi \frac{\rho_{s}}{\rho_{f}}}\left[\frac{1}{(1-\phi)^{2.5}} f^{\prime \prime \prime}+\left((1-\phi)+\phi \frac{(\rho \beta)_{s}}{(\rho \beta)_{f}}\right)\right) \lambda \theta\right]+\frac{1}{2} f f^{\prime \prime}=\xi\left(f^{\prime} \frac{\partial f^{\prime}}{\partial \xi}-f^{\prime \prime} \frac{\partial f}{\partial \xi}\right)$

$$
\begin{aligned}
& \frac{1}{(1-\phi)+\phi \frac{\left(\rho C_{p}\right)_{s}}{\left(\rho C_{p}\right)_{f}}}\left[\frac{1}{P r}\left(\frac{k_{n f}}{k_{s}}\right) \theta^{\prime \prime}\right] \\
& +\frac{1}{2} f \theta^{\prime}=\xi\left(f^{\prime} \frac{\partial \theta}{\partial \xi}-\theta^{\prime} \frac{\partial f}{\partial \xi}\right)
\end{aligned}
$$

along with

\section{Numerical method}

We introduce local similarity method for approximating nonlinear PDEs (1)-(3) into a set of nonlinear ODEs. Then, quasilinearization technique (Appendix I) has been introduced to linearized the coupled nonlinear ODEs (9)(10). In this quasilinearization technique, the nonlinear terms are linearizes around a solution profile satisfying 

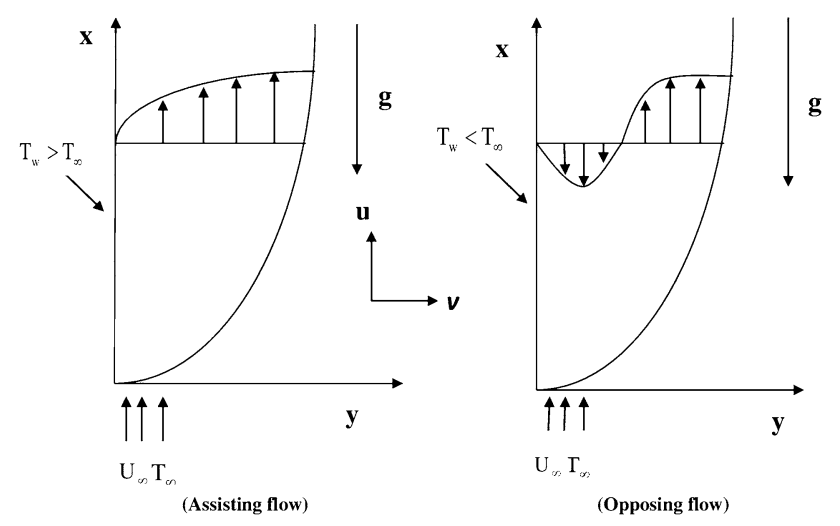

Fig. 1 Buoyancy-induced $\mathbf{a}$ assisting and $\mathbf{b}$ opposing flow

the boundary conditions (8). Then, for the solutions, linearized equations are then integrated numerically by introducing a implicit trapezoidal rule which is numerically stable [35] along with the method of principle of superposition. It has been noted that there are no significant changes on the predicted numerical results for $\eta(>10)$. Thus, $\eta_{\infty}=10$ has been taken for computational purpose. Also, we have found dual solutions for different nominal profiles.

\section{Results and discussion}

In the study of boundary layer flow under mixed convection, a numerical study has been made to investigate the behavior of flow variables for buoyancy-induced assisting and buoyancy-induced opposing flow cases for a semiinfinite flat vertically upward plate for different nanofluids. Seven different water-based nanofluids with nanoparticles such as alumina $\left(\mathrm{Al}_{2} \mathrm{O}_{3}\right)$, silver $(\mathrm{Ag})$, silica $\left(\mathrm{SiO}_{2}\right)$, copper $(\mathrm{Cu})$, titanate $\left(\mathrm{TiO}_{2}\right)$, zinc oxide $(\mathrm{ZnO})$, and copper oxide $(\mathrm{CuO})$ are taken to analyze the behavior of different nanofluids. The properties of water and solid nanoparticles are illustrated in Table 1. The predicted values $f^{\prime \prime}(\xi, 0)$ and $-\theta^{\prime}$ $(\xi, 0)$ are plotted for different $\eta_{\infty}$ in Figs 2 and 3 . The step size $\Delta \eta=0.1$ has been taken for numerical computations

Table 1 Properties for water and nanoparticles [34, 39]

\begin{tabular}{lllll}
\hline Materials & $\rho\left(\mathrm{kgm}^{-3}\right)$ & $k\left(\mathrm{Wm}^{-1} \mathrm{~K}^{-1}\right)$ & $\beta \times 10^{-5}\left(\mathrm{~K}^{-1}\right)$ & $C_{p}\left(\mathrm{~kg}^{-1} \mathrm{~K}^{-1}\right)$ \\
\hline $\mathrm{H}_{2} \mathrm{O}$ & 997.1 & 0.61 & 21 & 4179 \\
$\mathrm{Ag}$ & 10500 & 429 & 1.89 & 235 \\
$\mathrm{Al}_{2} \mathrm{O}_{3}$ & 3970 & 40 & 0.85 & 765 \\
$\mathrm{Cu}$ & 8933 & 401 & 1.67 & 385 \\
$\mathrm{SiO}_{2}$ & 2200 & 1.2 & 0.06 & 703 \\
$\mathrm{TiO}_{2}$ & 4250 & 8.95 & 0.9 & 686.2 \\
$\mathrm{CuO}_{\mathrm{ZnO}}$ & 6320 & 76.5 & 1.8 & 531.8 \\
\hline
\end{tabular}

Table 2 Results validation with the previous studies for $\left(-\theta^{\prime}(0,0)\right)$ with $\lambda=0$ and $\phi=0$ for different $\operatorname{Pr}$

\begin{tabular}{lllll}
\hline $\operatorname{Pr}$ & $\begin{array}{l}\text { Kuznetsov and } \\
\text { and Nield [40] }\end{array}$ & $\begin{array}{l}\text { Aydin and } \\
\text { Kaya[41] }\end{array}$ & $\begin{array}{l}\text { Chamkha } \\
\text { et al[42] }\end{array}$ & $\begin{array}{l}\text { Present } \\
\text { study }\end{array}$ \\
\hline 0.01 & - & 0.051437 & 0.05183 & 0.05714 \\
0.1 & 0.158 & 0.148123 & 0.142003 & 0.150812 \\
1 & 0.332 & 0.332 & 0.332173 & 0.332076 \\
10 & 0.73 & 0.727801 & 0.72831 & 0.728342 \\
100 & 1.57 & 1.573141 & 1.5721 & 1.574087 \\
\hline
\end{tabular}

as it gives the grid independent solutions for $\eta_{\infty}=10$. The effect of physical parameters involved in the problem such as $\lambda, \phi, R_{i}, \operatorname{Pr}$, and $\xi$ has been analyzed in the study. After the simulation, the predicted numerical results are displayed in tabular and graphical forms. Table 2 gives the code validation results for $\lambda=0$ (forced convection) and it is compared with the existing results. It is observed that there is excellent agreement of our present study with previous existing results. Further, we have validated our code with the results of stagnation flow problem with constant temperature over a vertical surface by adding the terms $\left(1-f^{\prime 2}\right)$ and $-f \theta^{\prime}$ in the governing equations (9) and (10), respectively, for $\phi=0$. The results for $f^{\prime \prime}(\xi, 0)$ and $\theta^{\prime}(\xi, 0)$ are validated with previous work of Lok et al. [36], Ramachandran et al. [9], Hassanien and Gorla [37], Ishak et al. [13] as shown in Tables 3 and 4. It seems to be a good agreement with those previous results. Therefore, our developed inhouse code can confidently used for numerical computations for our studies.

Figures 4, 5, 6 and 7 display the variation in $C_{f_{r d}}$ and $N u_{r d}$ with the variation in $\lambda$ for different $\phi$ and Pr. These figures showed the existence of dual solutions, and the dual solutions exist for $\lambda_{c r}<\lambda<0$ only for opposing flows $(\lambda<0)$ for the parameters $\phi$ and $\operatorname{Pr}$, where $\lambda_{c r}$ being the critical values of $\lambda$ and beyond $\lambda_{c r}$, the dual solutions do not exist, whereas, for buoyancy-induced assisting flow $(\lambda \geq 0)$, the present numerical method also gives unique solution.

Further, the values of $\lambda_{c r}$ decrease with increasing $\phi$ and such computed values of $\lambda_{c r}$ are $-0.315,-0.331,-0.357$ $,-0.382,-0.402$ for different $\phi=0.0,0.02,0.05,0.08,0.1$, respectively (Fig. 4), and for different $\operatorname{Pr}=0.1,1.0,10,100$ such values are $-0.143,-0.211,-0.413,-0.858$, respectively (Fig. 6). Thus, the predicted range of $\lambda_{c r}$ gradually increases with increasing $\phi$ and Pr. Also, it is observed that the upper solutions (solid lines) are stable and give realistic predictions, whereas the lower solutions (dotted lines) are very much sensitive with initial nominal solution profiles. Further, the nature of dual solutions for both velocity and thermal profiles are plotted for different $\phi$ in Figs. 8, 9, 10 and 11. It has been observed that for upper solution, velocity profiles are increased, whereas they are 
Fig. 2 Velocity profile for different $\eta_{\infty}$
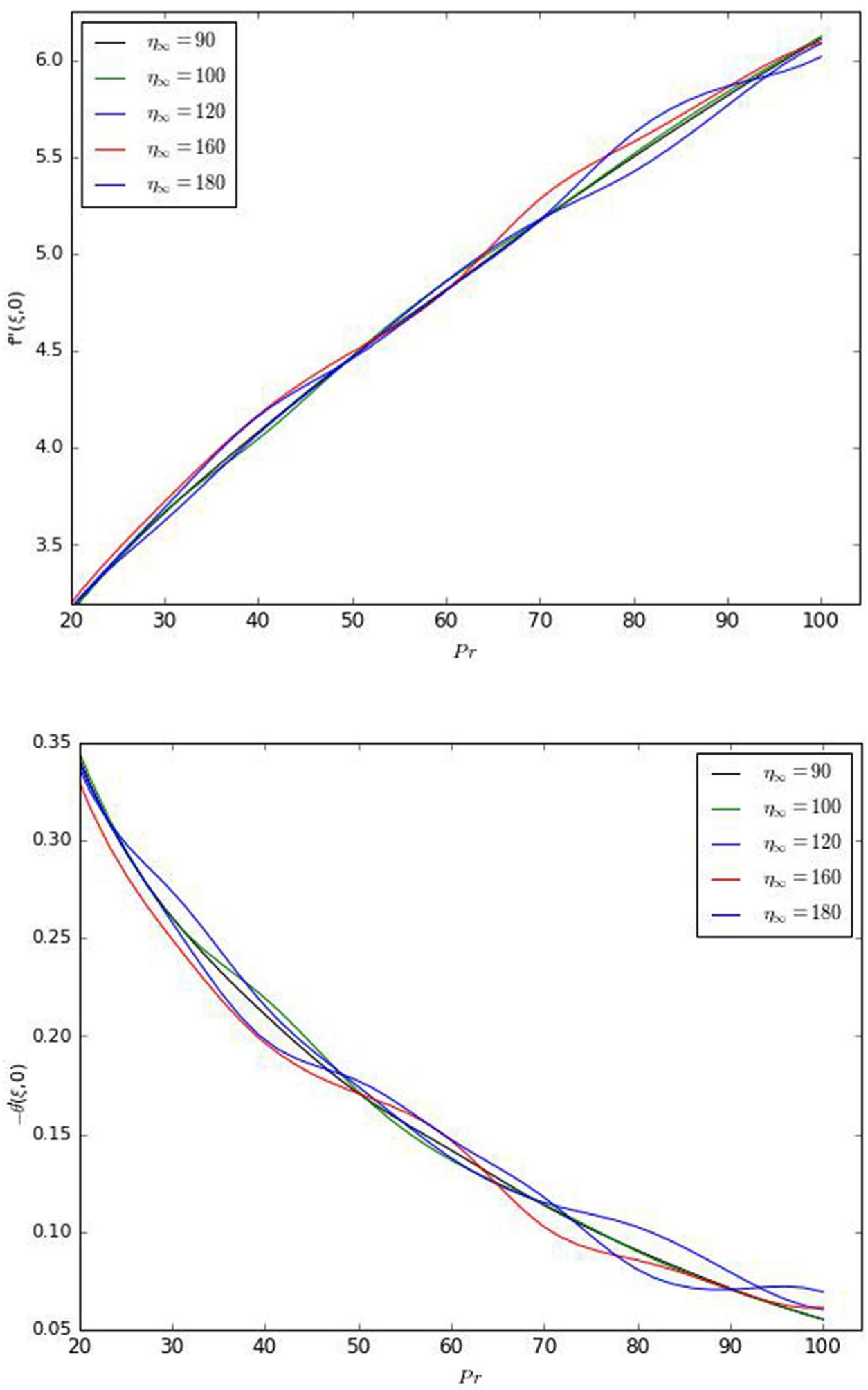

Fig. 3 Temperature profile for different $\eta_{\infty}$ decreased for the lower solution with increasing $\phi$ and the temperature profiles are increased for both the solutions with the increase in $\phi$.

The effects of $\phi, \operatorname{Pr}, R_{i}$ and $\xi$ on the dimensionless velocity profile $f^{\prime}(\xi, \eta)$ and temperature profile $\theta(\xi, \eta)$ are plotted in Figs. 12, 13, 14, 15, 16 and 17 for the $\mathrm{Ag}$ water nanofluid for buoyancy assisting flow $(\lambda>0)$. Figure 12 displays the velocity profiles $f^{\prime}(\xi, \eta)$ for different $\phi$ and $\xi$. It is observed that with the increase in $\phi, f^{\prime}(\xi, \eta)$ 


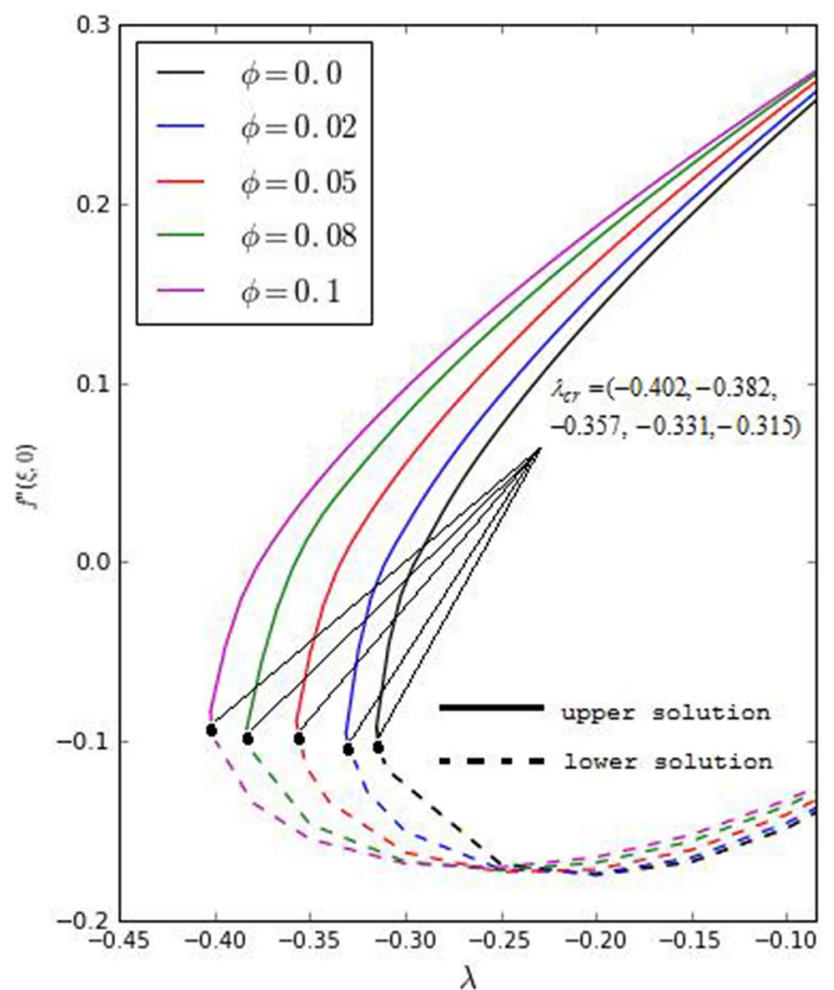

Fig. 4 Profiles for $f^{\prime \prime}(\xi, 0)$ for $\phi=0,0.02,0.05,0.08$ and 0.1 with fixed $\operatorname{Pr}=6.7$ for $\lambda<0$

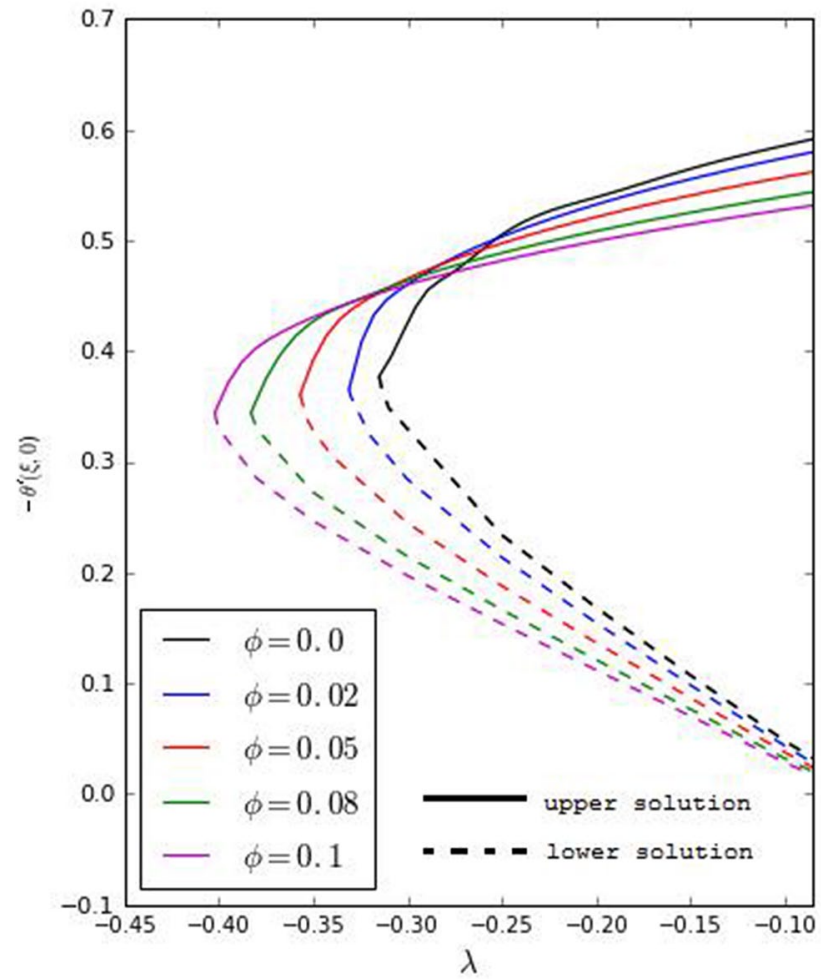

Fig. 5 Profiles for $-\theta^{\prime}(\xi, 0)$ for $\phi=0,0.02,0.05,0.08$ and 0.1 with fixed $\operatorname{Pr}=6.7$ for $\lambda<0$

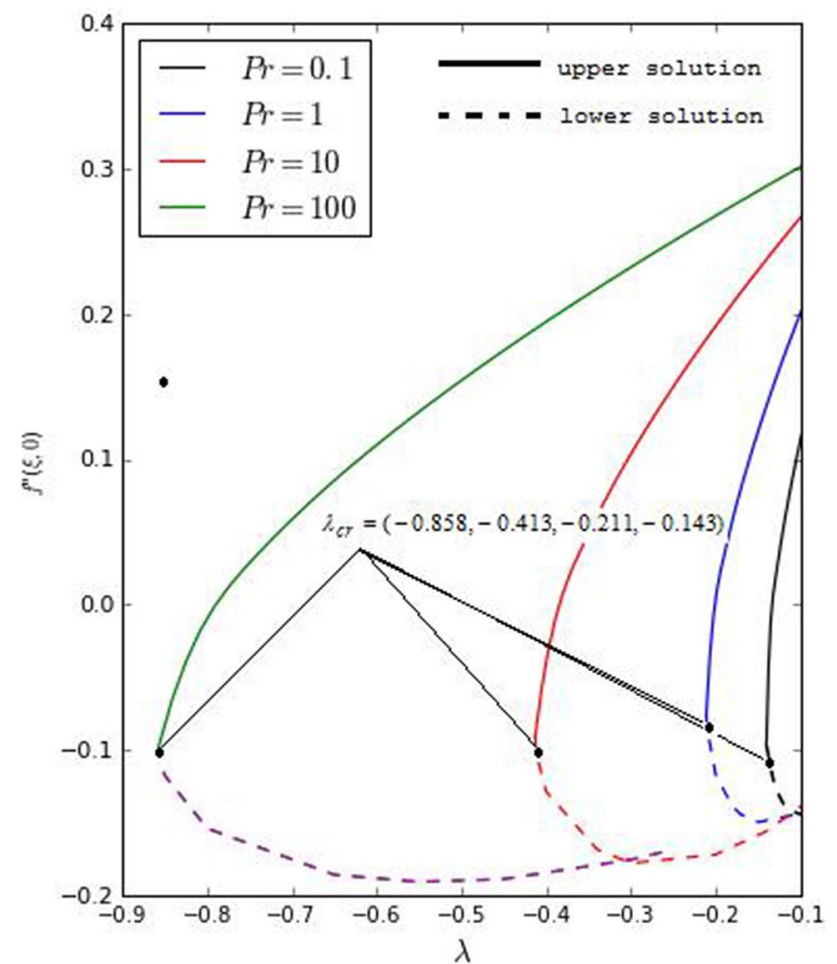

Fig. 6 Profiles for $f^{\prime \prime}(\xi, 0)$ for $\operatorname{Pr}=0.1,1,10$ and 100 for buoyancy opposing flow $(\lambda<0)$ for fixed $\phi=0.05$

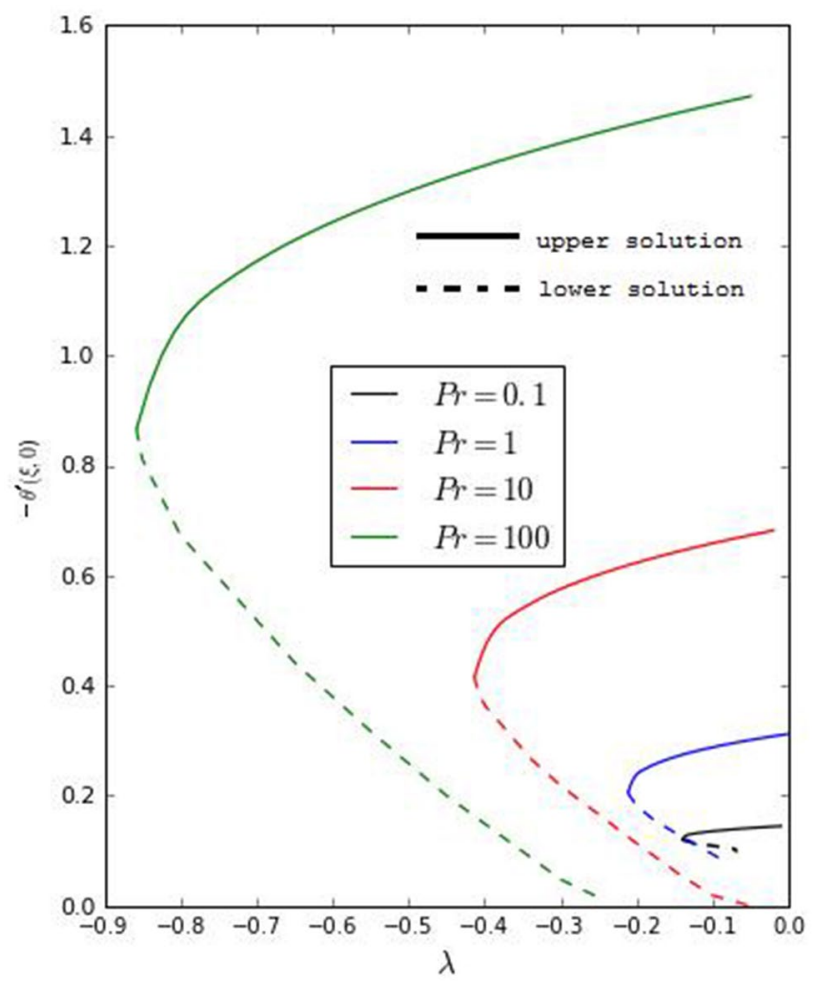

Fig. 7 Profiles for $\theta^{\prime}(\xi, 0)$ for $\operatorname{Pr}=0.1,1,10$ and 100 for buoyancy opposing flow $(\lambda<0)$ for fixed $\phi=0.05$ 


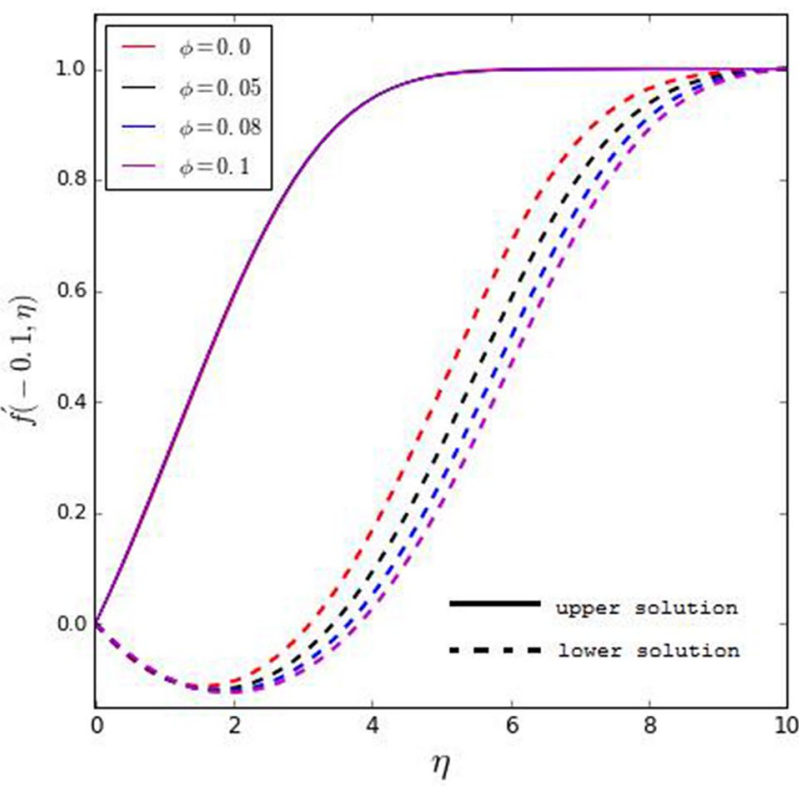

Fig. 8 Profiles for $f^{\prime}(-0.1, \eta)$ for different $\phi=0.05$ for buoyancy opposing flow $(\lambda<0)$ for fixed $\operatorname{Pr}=6.7$

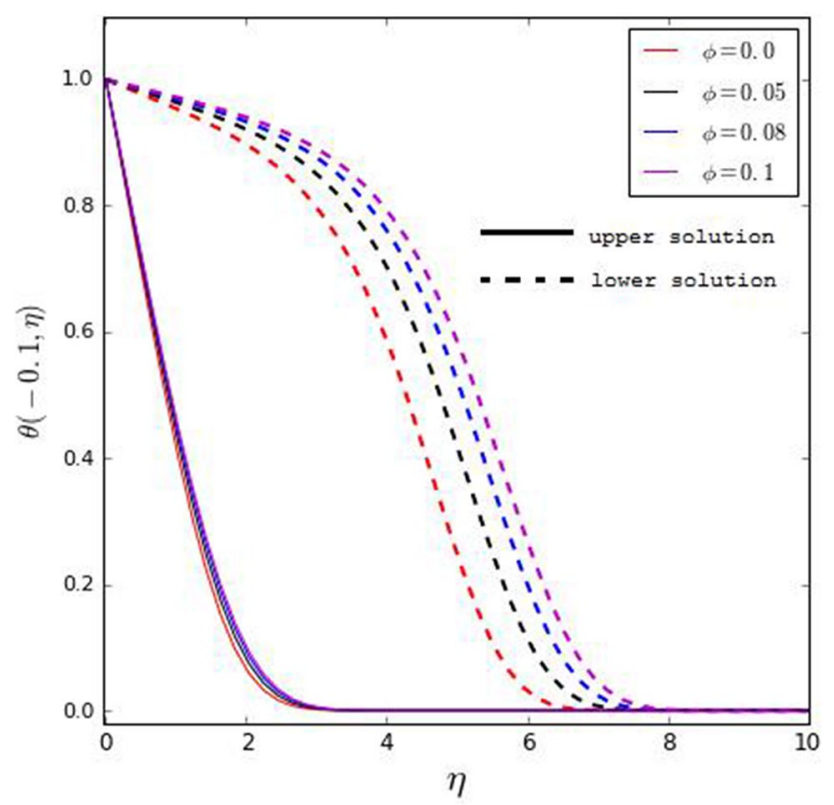

Fig. 9 Profiles for $\theta(-0.1, \eta)$ for different $\phi=0.05$ for buoyancy opposing flow $(\lambda<0)$ for fixed $\operatorname{Pr}=6.7$

decreases and it increases with increasing $\xi$, whereas $\theta(\xi, \eta)$ is increased for increasing $\phi$ and it decreases when $\xi$ increases (Fig. 13).

In the mixed convection phenomena, the significant effect of buoyancy is characterized by the parameter $\lambda$ where $\lambda=R_{i} \xi . R_{i}$, the Richardson number, a

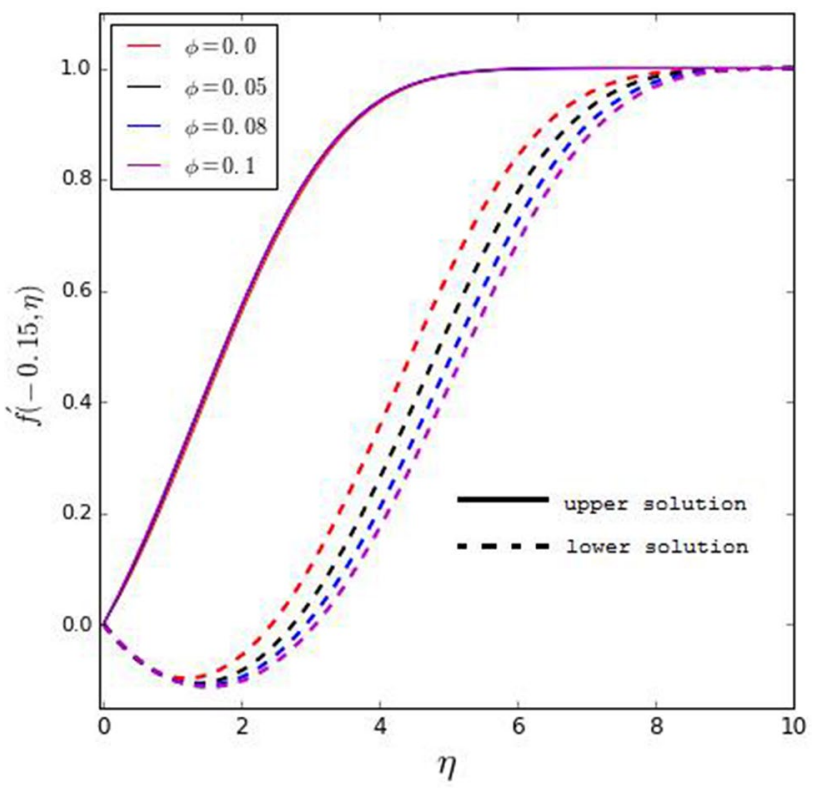

Fig. 10 Profiles for $f^{\prime}(-0.15, \eta)$ for different $\phi=0.05$ for buoyancy opposing flow $(\lambda<0)$ for fixed $\operatorname{Pr}=6.7$

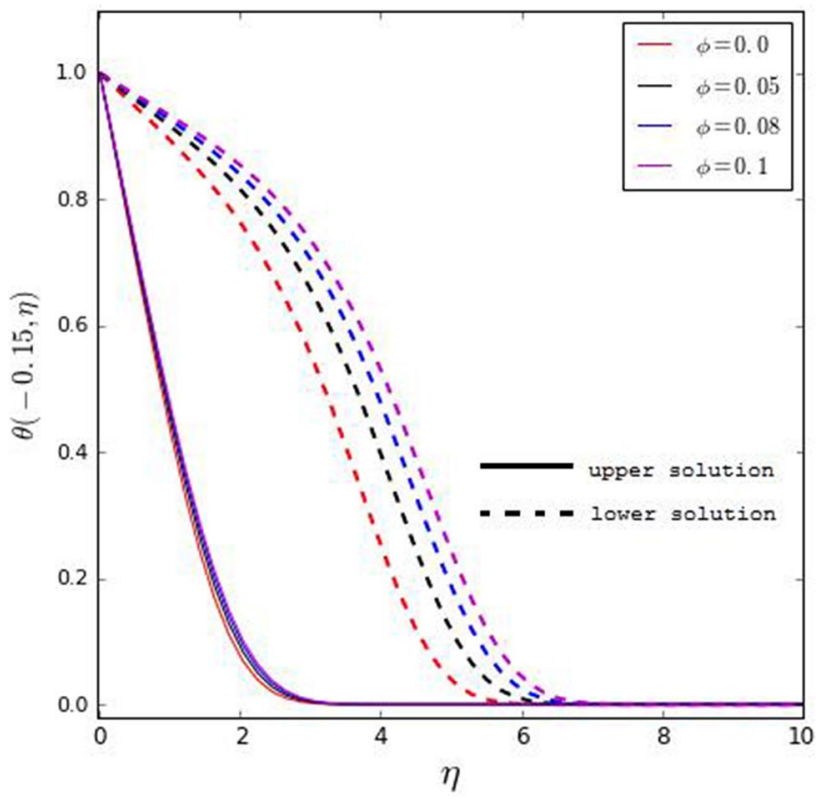

Fig. 11 Profiles for $\theta(-0.15, \eta)$ for different $\phi=0.05$ for buoyancy opposing flow $(\lambda<0)$ for fixed $\operatorname{Pr}=6.7$

non-dimensional parameter is defined in terms of the ratio between two non-dimensional parameters, i.e., Grashof number $(\mathrm{Gr})$ and Reynolds number (Re), respectively. Therefore, when $R_{i}$ increases, then there is an decrements in $R e$, i.e., it causes the less viscous effect which results the dominance in rising fluid. Thus, with the increase in $R_{i}$, there is a increment in velocity boundary layer and 
Table 3 For different Pr the values of $f^{\prime \prime}(\xi, 0)$ with $\lambda=1$

\begin{tabular}{|c|c|c|c|c|c|}
\hline $\operatorname{Pr}$ & $\begin{array}{l}\text { Ramachandran } \\
\text { et al [9] }\end{array}$ & $\begin{array}{l}\text { Hassanien } \\
\text { and Gorla [37] }\end{array}$ & $\begin{array}{l}\text { Lok } \\
\text { et al [36] }\end{array}$ & $\begin{array}{l}\text { Ishak et al [13] } \\
\text { First Second } \\
\text { solution solution }\end{array}$ & $\begin{array}{l}\text { Present study } \\
\text { First Second } \\
\text { solution solution }\end{array}$ \\
\hline 0.7 & 1.7063 & 1.70632 & 1.7064 & 1.70631 .2387 & 1.7069121 .238375 \\
\hline 1 & - & - & - & $1.6754 \quad 1.1332$ & $1.674278 \quad 1.131989$ \\
\hline 7 & 1.5179 & - & 1.5180 & 1.51790 .5824 & 1.1519970 .583661 \\
\hline 10 & - & 1.49284 & - & 1.49280 .4958 & 1.4929310 .495841 \\
\hline 20 & 1.4485 & - & 1.4486 & 1.44850 .3436 & 1.449730 .337137 \\
\hline 40 & 1.4101 & - & 1.4102 & 1.41010 .2111 & $1.410305 \quad 0.215425$ \\
\hline 50 & - & 1.40686 & - & 1.39890 .1720 & 1.3999620 .174368 \\
\hline 60 & 1.3903 & - & 1.3903 & 1.39030 .1413 & 1.3904970 .137669 \\
\hline 80 & 1.3774 & - & 1.3773 & 1.37740 .0947 & 1.3764390 .102407 \\
\hline 100 & 1.3680 & 1.38471 & 1.3677 & 1.36800 .0601 & $1.371214 \quad 0.060135$ \\
\hline
\end{tabular}

Table 4 For different $\operatorname{Pr}$ the values of $-\theta^{\prime}(\xi, 0)$ with $\lambda=1$

\begin{tabular}{|c|c|c|c|c|c|}
\hline $\operatorname{Pr}$ & $\begin{array}{l}\text { Ramachandran } \\
\text { et al [9] }\end{array}$ & $\begin{array}{l}\text { Hassanien } \\
\text { and Gorla [37] }\end{array}$ & $\begin{array}{l}\text { Lok } \\
\text { et al [36] }\end{array}$ & $\begin{array}{l}\text { Ishak et al [13] } \\
\text { First Second } \\
\text { solution solution }\end{array}$ & $\begin{array}{l}\text { Present study } \\
\text { First Second } \\
\text { solution solution }\end{array}$ \\
\hline 0.7 & 0.7641 & 0.76406 & 0.7641 & $0.7641 \quad 1.0226$ & 0.7441471 .021922 \\
\hline 1 & - & - & - & $0.8708 \quad 1.1691$ & $0.870197 \quad 1.168903$ \\
\hline 7 & 1.7224 & - & 1.7226 & 1.72242 .2192 & 1.17218512 .214216 \\
\hline 10 & - & 1.94461 & - & 1.94462 .4940 & $1.943092 \quad 2.489550$ \\
\hline 20 & 2.4576 & - & 2.4577 & $2.4576 \quad 3.1646$ & $2.454101 \quad 3.174164$ \\
\hline 40 & 3.1011 & - & 3.1023 & 3.10114 .1080 & $3.093509 \quad 4.072381$ \\
\hline 50 & - & 3.34882 & - & 3.34154 .4976 & $3.333499 \quad 4.465524$ \\
\hline 60 & 3.5514 & - & 3.5560 & $3.5514 \quad 4.8572$ & $3.541530 \quad 4.858395$ \\
\hline 80 & 3.9095 & - & 3.9195 & $3.9095 \quad 5.5166$ & $3.902441 \quad 5.423155$ \\
\hline 100 & 4.2116 & 4.23372 & 4.2289 & $4.2116 \quad 6.1230$ & $4.212591 \quad 5.834113$ \\
\hline
\end{tabular}

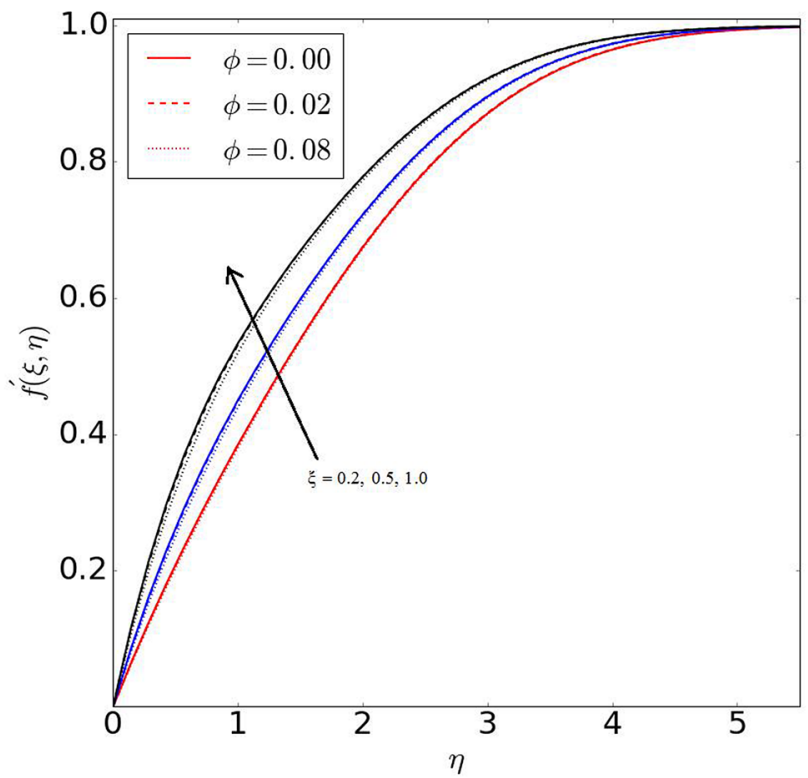

Fig. 12 Velocity profile with different $\phi$ and $\xi=0.2,0.5,1$ for $\mathrm{Al}_{2} \mathrm{O}_{3}$ -water nanofluid

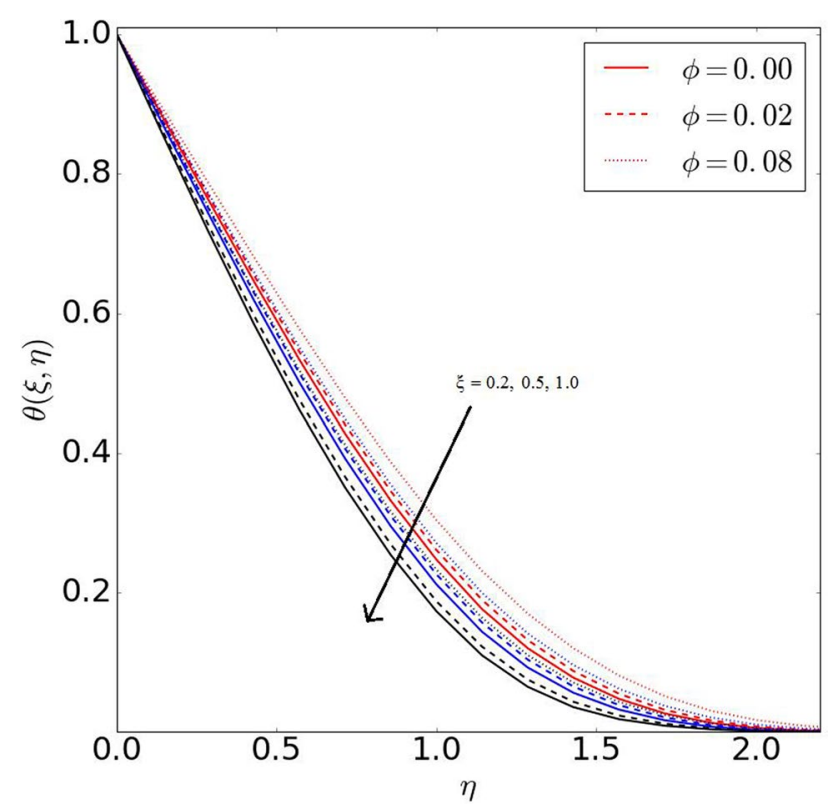

Fig. 13 Temperature profile with different $\phi$ and $\xi=0.2,0.5,1$ for $\mathrm{Al}_{2} \mathrm{O}_{3}$-water nanofluid

\section{SN Applied Sciences}


reduction in temperature in the boundary layer. The same phenomena have been observed in the predicted results as shown in Figs 14 and 15.

Figures 16 and 17 are plotted to see the effect of another non-dimensional parameter, PrandtI number, $P r$ on $f^{\prime}(\xi, \eta)$ and $\theta(\xi, \eta)$, respectively. The Prandtl number is defined between the ratio of momentum diffusivity and thermal diffusivity. Therefore, with increasing Pr, viscosity will be dominant over the thermal diffusivity. Thus, for higher Pr, both velocity and thermal boundary layer thicknesses decrease. Thus, the local Nusselt number gives a significantly higher values. Thus, Prandtl number plays a significant role for enhancing the process of heat transfer. In our study, the predicted results for higher values of $\operatorname{Pr}$ have followed same observations as shown in the velocity and temperature profiles (Figs. 16 and 17).

The velocity and temperature distributions for various nanofluids (with nanoparticle $\mathrm{Al}_{2} \mathrm{O}_{3}, \mathrm{Cu}, \mathrm{CuO}, \mathrm{Ag}, \mathrm{ZnO}, \mathrm{TiO}_{2}$ and $\mathrm{SiO}_{2}$ and base fluid as water has been considered) are plotted in Figs. 18 and 19 for fixed $\xi=0.5$ and $\phi=0.05$. It has been observed that velocity and temperature distribution are faster for $\mathrm{Ag}$-water nanofluid, whereas it is lower for $\mathrm{SiO}_{2}$-water nanofluid. The order of increasing in velocities has been maintained with the increasing order in thermal conductivities of solid nanoparticles. The temperature reduction for $\mathrm{Ag}$-water nanofluid is faster and lower for $\mathrm{SiO}_{2}$-water nanofluid (Fig. 19). Figures 20 and 21 illustrate the variation in $C_{f_{r d}}$ and $N u_{r d}$ for all nanofluids at
Table 5 Results for $C_{f_{r d}}$ and $N u_{r d}$ for various $\phi, \xi$ for buoyancyinduced opposing flow $(\lambda 0)$ for fixed $\operatorname{Pr}=6.7$
Table 6 Results for $C_{f_{r d}}$ and $N u_{r d}$ for various $\operatorname{Pr}, \xi$ for buoyancyinduced opposing flow $(\lambda<0)$ for fixed $\phi=0.05$

\begin{tabular}{lllllll}
\hline$\phi$ & $\xi$ & $C_{f}(R e)^{0.5}$ & & & $N u_{x}(R e)^{-0.5}$ & \\
& & Upper Solution & Lower solution & & Upper Solution & Lower solution \\
\hline 0.0 & -0.1 & 0.486266 & -0.29777 & & 0.585602 & 0.048 \\
& -0.2 & 0.278312 & -0.34958 & & 0.538711 & 0.16842 \\
& -0.3 & 0.0003 & -0.230 & & 0.40447 & 0.34846 \\
0.02 & -0.1 & 0.523348 & -0.30695 & & 0.607899 & 0.046117 \\
& -0.2 & 0.318175 & 0.36625 & & 0.563314 & 0.163721 \\
& -0.3 & 0.040297 & -0.31662 & & 0.486897 & 0.300488 \\
0.05 & -0.1 & 0.58122 & -0.32098 & & 0.640885 & 0.043271 \\
& -0.2 & 0.379327 & -0.39037 & & 0.599279 & 0.157304 \\
& -0.3 & 0.123579 & -0.36895 & & 0.535379 & 0.281674 \\
0.08 & -0.1 & 0.642219 & -0.33579 & & 0.673376 & 0.040118 \\
& -0.2 & 0.442805 & -0.41391 & & 0.634333 & 0.151384 \\
& -0.3 & 0.200678 & -0.41227 & & 0.578495 & 0.267706 \\
0.1 & -0.1 & 0.684874 & -0.34644 & & 0.694789 & 0.03765 \\
& -0.2 & 0.486764 & -0.4295 & & 0.657281 & 0.147583 \\
& -0.3 & 0.251228 & -0.4386 & 0.605536 & 0.25980 \\
\hline
\end{tabular}

\begin{tabular}{|c|c|c|c|c|c|}
\hline \multirow[t]{2}{*}{$P r$} & \multirow[t]{2}{*}{$\xi$} & \multicolumn{2}{|l|}{$C_{f}(R e)^{0.5}$} & \multicolumn{2}{|l|}{$N u_{x}(R e)^{-0.5}$} \\
\hline & & Upper Solution | & Lower solution & Upper Solution | & Lower solution \\
\hline \multirow[t]{3}{*}{0.1} & -0.1 & 0.25669 & -0.32837 & 0.156088 & 0.12781 \\
\hline & -0.12 & 0.11945 & -0.311690 & 0.152138 & 0.130269 \\
\hline & -0.13 & 0.03425 & -0.28676 & 0.149389 & 0.133304 \\
\hline \multirow[t]{3}{*}{1.0} & -0.1 & 0.455396 & -0.32752 & 0.33147 & 0.107863 \\
\hline & -0.15 & 0.269992 & -0.340827 & 0.3110659 & 0.153455 \\
\hline & -0.2 & 0.008239 & -0.266027 & 0.274597 & 0.209236 \\
\hline \multirow[t]{4}{*}{10} & -0.1 & 0.605501 & -0.3167084 & 0.7578077 & 0.021960 \\
\hline & -0.2 & 0.435442 & -0.391513 & 0.717245 & 0.130792 \\
\hline & -0.3 & 0.23530 & -0.405096 & 0.662232 & 0.251446 \\
\hline & -0.4 & 0.0182709 & -0.292792 & 0.588664 & 0.419798 \\
\hline \multirow[t]{3}{*}{100} & -0.45 & 0.174834 & -0.189108 & 1.322295 & 0.200265 \\
\hline & -0.65 & 0.085358 & -0.186114 & 1.209327 & 0.442606 \\
\hline & -0.75 & 0.28637 & -0.154213 & 1.125163 & 0.673400 \\
\hline
\end{tabular}


Table 7 Effect of $\phi$ and $\xi$ on $f^{\prime \prime}(\xi, 0)$ profile near separation point $(\lambda<0)$ for fixed $\operatorname{Pr}=6.7$

\begin{tabular}{lllll}
\hline$\xi$ & $f^{\prime \prime}(\xi, 0)$ & & \\
\cline { 2 - 5 } & $\phi=0.0$ & $\phi=0.02$ & $\phi=0.05$ & $\phi=0.08$ \\
\hline 0.2939 & 0.00018 & 0.019156 & 0.054353 & 0.081459 \\
0.31 & - & 0.00053 & 0.040065 & 0.061459 \\
0.33 & - & - & 0.00074 & 0.044463 \\
0.3850 & - & - & - & 0.00015 \\
\hline
\end{tabular}

Table 8 Effect of $\operatorname{Pr}$ and $\xi$ on $f^{\prime \prime}(\xi, 0)$ profile near separation point $(\lambda<0)$ for $\phi=0.05$

\begin{tabular}{lllll}
\hline$\xi$ & $f^{\prime \prime}(\xi, 0)$ & & \\
\cline { 2 - 5 } & $\operatorname{Pr}=0.1$ & $\operatorname{Pr}=1$ & $\operatorname{Pr}=10$ & $\operatorname{Pr}=100$ \\
\hline 0.1330 & 0.001729 & 0.118749 & 0.222566 & 0.284655 \\
0.2011 & - & 0.003624 & 0.191518 & 0.257588 \\
0.390 & - & - & 0.008036 & 0.194608 \\
0.7879 & - & - & - & 0.001972 \\
\hline
\end{tabular}

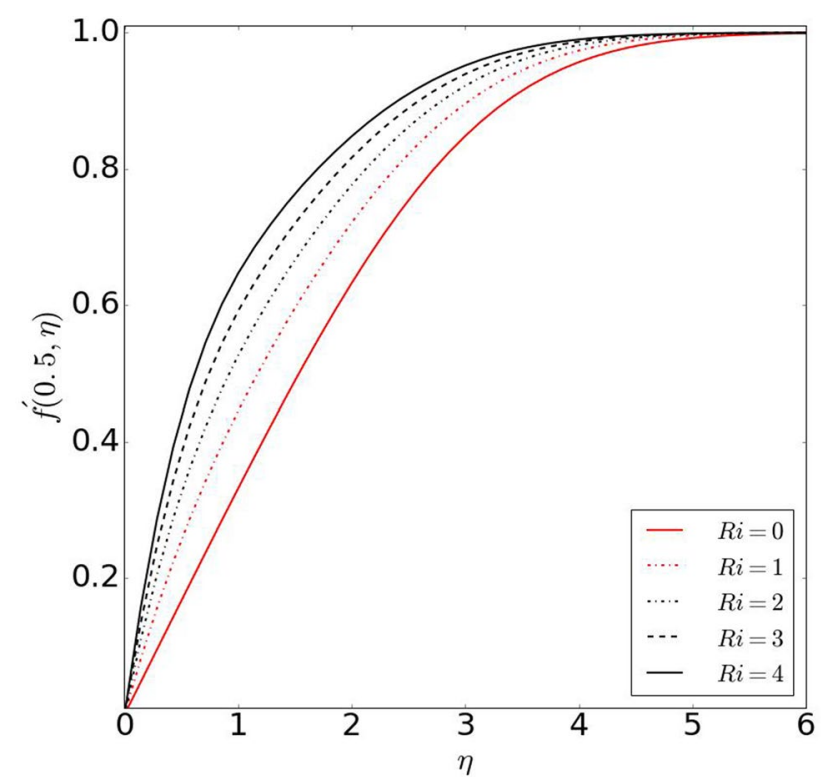

Fig. 14 Velocity Profile with different $R_{i}$ with fixed $\xi=0.5$ and $\phi=0.05$ for $\mathrm{Al}_{2} \mathrm{O}_{3}$-water nanofluids

$\xi=0.5$ and for fixed $\phi=0.05$. The increment for both the parameters is much faster for $\mathrm{Ag}$-water nanofluid, whereas for $\mathrm{SiO}_{2}$-water nanofluid these are lower for both the cases. However, Nusselt number decreases slightly for $\mathrm{SiO}_{2}$-water nanofluid with the increase of $\phi$ (Fig. 21).

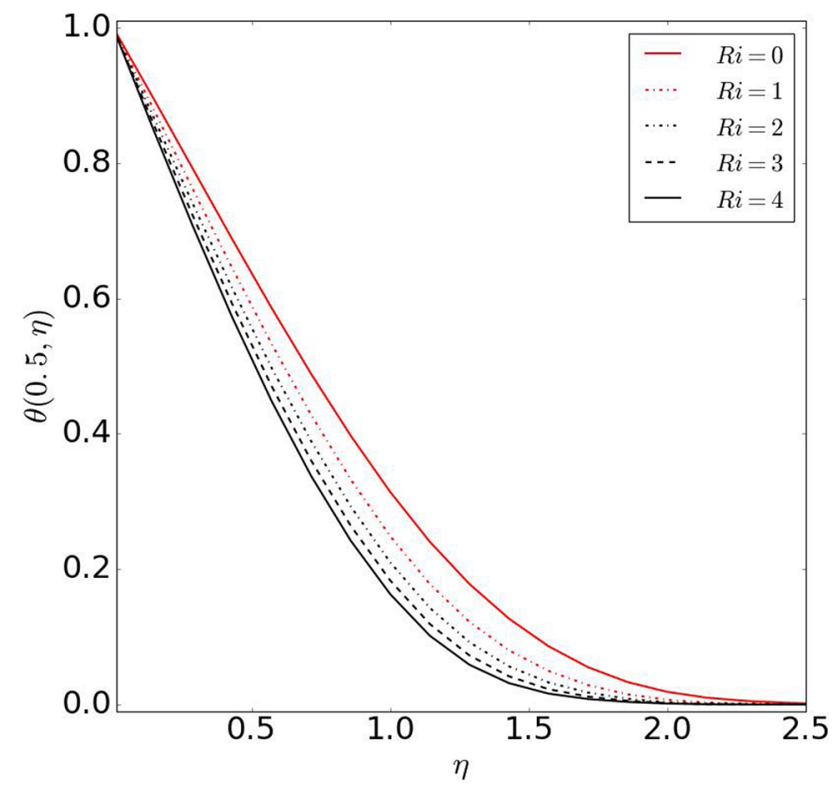

Fig. 15 Temperature Profile with different $R_{i}$ with fixed $\xi=0.5$ and $\phi=0.05$ for $\mathrm{Al}_{2} \mathrm{O}_{3}$-water nanofluids

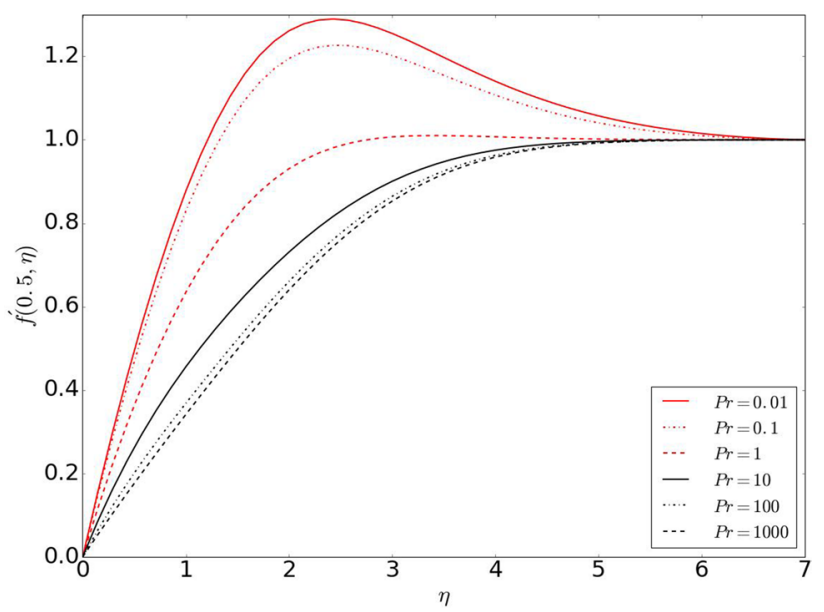

Fig. 16 Velocity Profile with various $\operatorname{Pr}$ with fixed $\xi=0.5$ and $\phi=0.05$ for $\mathrm{Al}_{2} \mathrm{O}_{3}$-water nanofluids

The variation in the predicted results for $C_{f_{r d}}$ and $N u_{r d}$ is displayed in Table 5 and 6 . In the tables, the behavior of $C_{r_{r d}}$ and $N u_{r d}$ has shown for the solutions of opposing flow case $(\lambda<0)$. It observes that the predicted values of $C_{f_{r d}}$ in case of upper solutions are decreased with the increase in $\xi$, whereas $C_{f_{r d}}$ increases with increasing $\phi$ and Pr. Further, for lower solution, $C_{f_{r d}}$ increases first, and it then decreases with increasing $\xi$. Further, it increases with increasing $\phi$ and decreases for increasing $\operatorname{Pr}$. 


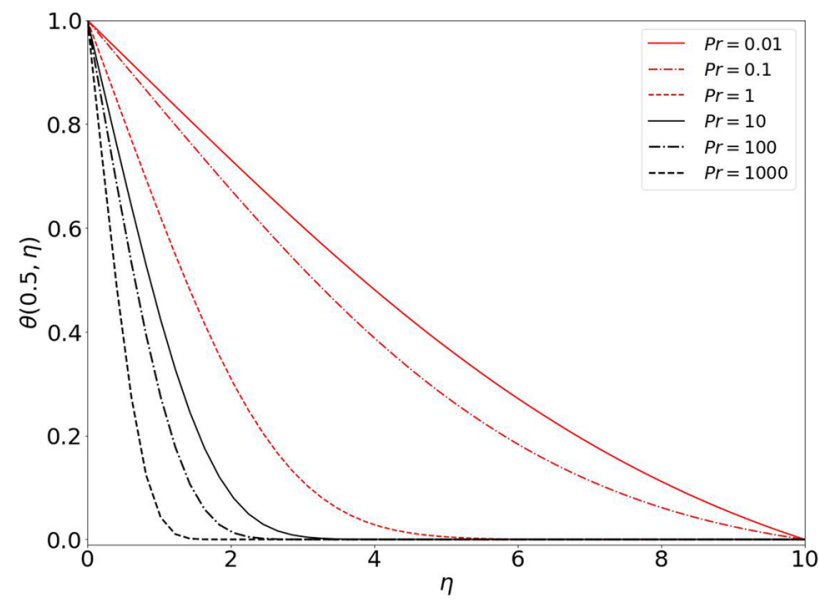

Fig. 17 Temperature Profile with various $\operatorname{Pr}$ with fixed $\xi=0.5$ and $\phi=0.05$ for $\mathrm{Al}_{2} \mathrm{O}_{3}$-water nanofluids

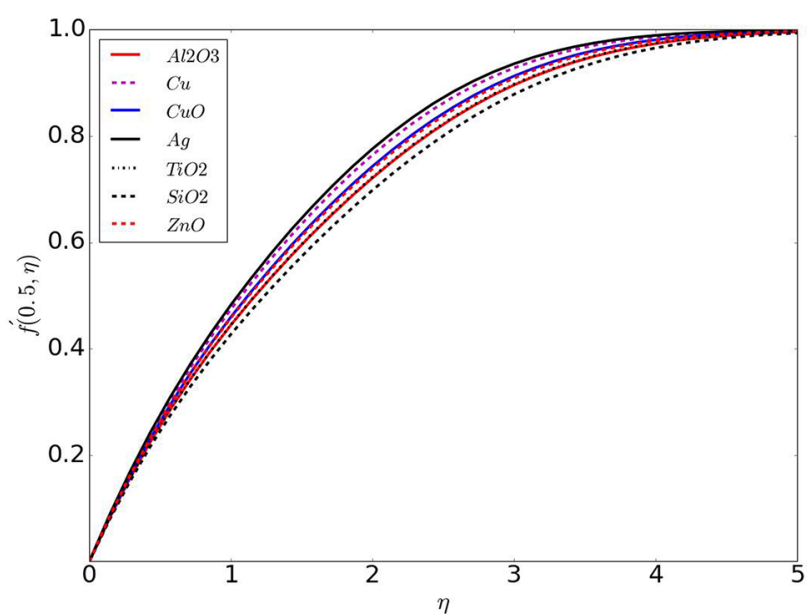

Fig. 18 Velocity profile for various nanofluids with $\xi=0.5$ and $\phi=0.05$

In case of $\mathrm{Nu}_{r d}$, it increases for upper solutions with increasing $\xi$ and decreases with increasing $\phi$ and $\operatorname{Pr}$. For lower solution, with the increase in $\xi, N u_{r d}$ increases and it decreases for increasing in both $\phi$ and Pr. However, for higher $\mathrm{Pr}, \mathrm{Nu}_{\mathrm{rd}}$ is increased for both the solutions. Further, the effect of different values of $\phi$ and $\operatorname{Pr}$ on the $f^{\prime \prime}(\xi, 0)$ has been discussed near separation point (wall shear stress is zero for opposing flow $(\lambda<0)$ ) as given in Tables 7 and 8, respectively. It has also been noted that with the increase in both $\phi$ and $P r$, the range of the separation points is also increased. Thus, it can be concluded that separation has been delayed with the increase in $\phi$ and Pr.

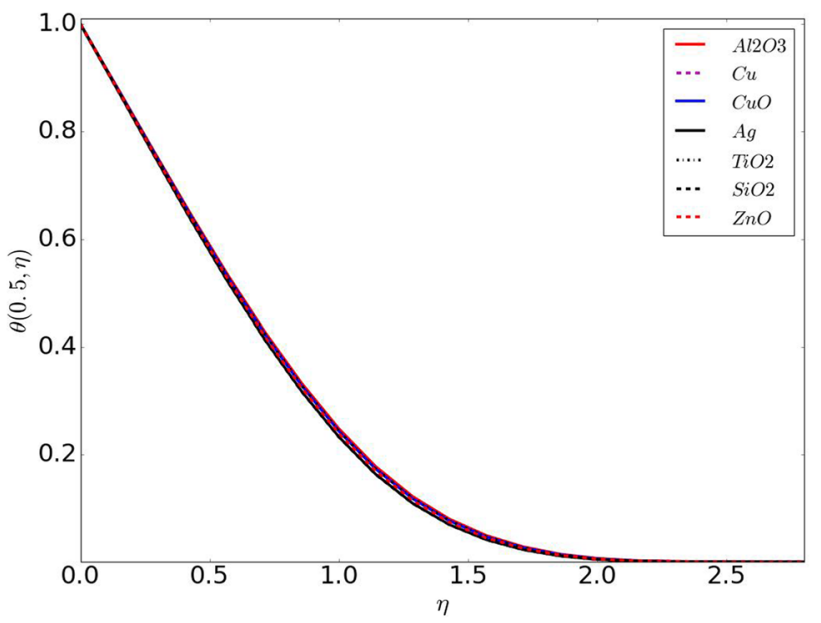

Fig. 19 Temperature profile for various nanofluids with fixed $\xi=0.5$ and $\phi=0.05$

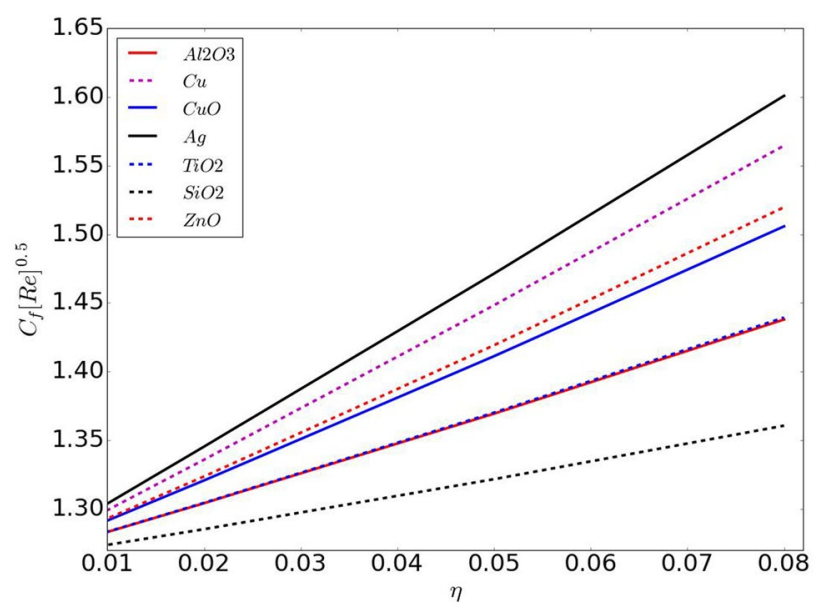

Fig. 20 Variation on $C f_{r d}$ with $\xi=0.5$ and $\phi=0.05$ for various nanofluids

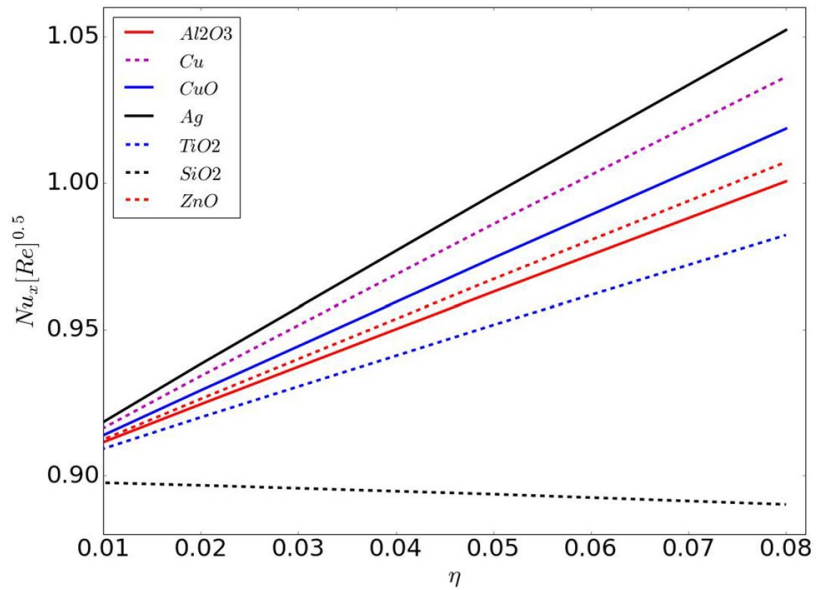

Fig. 21 Variation on $N u_{r d}$ for various nanofluids with fixed $\xi=0.5$ and $\phi=0.05$ 


\section{Conclusions}

Under steady-state condition, a numerical study has been made for boundary layer flow under mixed convection for different nanofluids over a flat plate which has been placed vertically. In this work, both buoyancyinduced assisting and opposing flow cases are considered. To analyze the effect of different physical parameters which are involved in the study, are presented through the figures and tables. The following conclusions are made:

1. The existence of dual solutions is found for buoyancyinduced opposing flow case. For increasing $\phi$ and $P r$, the existing range of dual solutions is increased. Moreover, this study says that the existing range of solutions gradually increases for increasing $\operatorname{Pr}$ as compared to increasing $\phi$.

2. $f^{\prime}(\xi, \eta)$ decreases and $\theta(\xi, \eta)$ increases with increasing $\phi$ for both the flow cases. Thus, with the inclusion of nanoparticles, enhancement occurs in heat transfer process.

3. It has been found that $A g$-water nanofluid shows the highest cooling performance where $\mathrm{SiO}_{2}$ water nanofluid is the lowest. This observation is followed as the thermal conductivity of $\mathrm{Ag}$ is higher, and for $\mathrm{SiO}_{2}$, it is lower.

4. The $C_{f_{r d}}$ and $N u_{r d}$ are increased in both the flow cases with the inclusion of nanoparticles. The behavior shows that nanofluids delay the point of separation for opposing flow.

Acknowledgements Srimanta Maji was funded partially by a research fellowship from Technical Education Quality Improvement Programme (TEQIP), Government of India.

\section{Declarations}

Conflict of interest The authors declare that they have no conflict of interest

Open Access This article is licensed under a Creative Commons Attribution 4.0 International License, which permits use, sharing, adaptation, distribution and reproduction in any medium or format, as long as you give appropriate credit to the original author(s) and the source, provide a link to the Creative Commons licence, and indicate if changes were made. The images or other third party material in this article are included in the article's Creative Commons licence, unless indicated otherwise in a credit line to the material. If material is not included in the article's Creative Commons licence and your intended use is not permitted by statutory regulation or exceeds the permitted use, you will need to obtain permission directly from the copyright holder. To view a copy of this licence, visit http://creativecommons. org/licenses/by/4.0/.

\section{Appendix. quasilinearization method}

In quasilinearization technique [38], the nonlinear terms are linearizes around a nominal solution through Taylor's series expansion by considering only first-order terms. The nominal profile satisfies the boundary conditions (11). After applying the quasilinearization technique to equations (9) and (10) for the $(i+1)$ th step in terms of $i$ th step and then simplifying, we obtain the linear ODEs as follows

$f_{i+1}^{\prime \prime \prime}+A_{i} f_{i+1}^{\prime \prime}+B_{i} f_{i+1}^{\prime}+C_{i} f_{i+1}+D_{i} f \theta_{i+1}=E_{i}$

and

$\theta_{i+1}^{\prime \prime}+P_{i} \theta_{i+1}^{\prime}+Q_{i} \theta_{i+1}+R_{i} f_{i+1}=F_{i}$

where $A_{i}=-\frac{1}{2}(1-\phi)^{2.5}\left((1-\phi)+\phi \frac{\rho_{s}}{\rho_{f}}\right) f_{i}, \quad B_{i}=0$,

$C_{i}=\frac{1}{2}(1-\phi)^{2.5}\left((1-\phi)+\phi \frac{\rho_{s}}{\rho_{f}}\right) f_{i}^{\prime \prime}$,

$\left.D_{i}=(1-\phi)^{2.5}\left((1-\phi)+\phi \frac{(\rho \beta)_{s}}{(\rho \beta)_{f}}\right)\right) \xi\left(\frac{G r}{R e^{2}}\right)$,

$E_{i}=(1-\phi)^{2.5}\left((1-\phi)+\phi \frac{\rho_{s}}{\rho_{f}}\right) \frac{1}{2} f_{i} f_{i}^{\prime \prime}$

and

$$
\begin{aligned}
& P_{i}=-\frac{1}{2} \operatorname{Pr}\left((1-\phi)+\phi \frac{\left(\rho C_{P}\right)_{s}}{\left(\rho C_{\rho_{f}}\right.}\right) f_{i}, \quad Q_{i}=0, \\
& R_{i}=\frac{1}{2} \operatorname{Pr}\left((1-\phi)+\phi \frac{\left(\rho C_{P}\right)_{s}}{\left(\rho \rho_{\rho}\right)_{f}}\right) \theta^{\prime}, \\
& F_{i}=\frac{1}{2} \operatorname{Pr}\left((1-\phi)+\phi \frac{\left(\rho C_{P}\right)_{s}}{\left(\rho C_{\rho}\right)_{f}}\right) f_{i} \theta_{i}^{\prime}
\end{aligned}
$$

Now, from equations (A.1) and (A.2), a set of first-order ODEs can be obtained by using shooting method and this can be written as

$\mathbf{y}_{i+1}^{\prime}=\mathbf{A}_{i} \mathbf{y}_{i+1}+\mathbf{B}_{i}$

where $\mathbf{A}_{i}$ is a $5 \times 5$ coefficient matrix; $\mathbf{y}=\left[f, f^{\prime}, f^{\prime \prime}, \theta, \theta^{\prime}\right]^{t}$ is a solution matrix of order $5 \times 1$.

\section{References}

1. Merkin JH (1969) The effect of buoyancy forces on the boundary-layer flow over a semi-infinite vertical flat plate in a uniform free stream. J Fluid Mechanics 35(3):439-450

2. Wilks G (1973) Combined forced and free convection flow on vertical surfaces. Int J Heat Mass Transf 16(10):1958-1962

3. Chen TS, Mucoglu A (1975) Buoyancy effects on forced convection along a vertical cylinder. ASME J Heat Transf 97:198-203

4. Hunt R, Wilks G (1980) On the behaviour of the laminar boundary-layer equations of mixed convection near a point of zero skin friction. J Fluid Mech 101(2):377-391

5. Wilks G, Bramley JS (1981) Dual solutions in mixed convection. Proc R Soc Edinb 87A:349-358

6. Merkin JH (1985) On dual solutions occurring in mixed convection in a porous medium. J Eng Math 20:171-179

7. Ishak A, Azar RN (2007) Dual solutions in mixed convection boundary-layer flow with suction or injection. IMA J Appl Math 72:451-463

8. Mahmood T, Merkin JH (1988) Similarity solutions in axisymmetric mixed-convection boundary-layer flow. J Eng Math 22:73-92 
9. Ramachandran N, Chen TS, Armaly BF (1998) Mixed convection in stagnation flows adjacent to a vertical surfaces. ASME J Heat Transfer 110:373-377

10. Ridha A (1996) Aiding flows non-unique similarity solutions of mixed-convection boundary-layer equations. J Appl Math Phys (ZAMP) 47:341-352

11. Weidman PD, Kubitschek DG, Davis AMJ (2006) The effect of transpiration on self-similar boundary layer flow over moving surfaces. Int J Eng Sci 44:730-737

12. $\mathrm{Xu} \mathrm{H}$, Liao SJ (2008) Dual solutions of boundary layer flow over an upstream moving plate. Commun Nonlinear Sci Numer Simulat 13:358-358

13. Ishak A, Nazar R, Arifin NM, Pop I (2008) Dual solutions in mixed convection flow near a stagnation point on a vertical porous plate. Int J Therm Sci 47(2):417-422

14. Afzal N, Badaruddii, Elgarvi AA (1993) Momentum and heat transport on a continuous stream flat surface moving in a parallel. Int J Heat Mass Transfer 36:3399-3403

15. Choi S (1995) Enhancing thermal conductivity of fluids with nanoparticles in developments and applications of non-newtonian flows. In: Siginer DA and Wang HP, editors,ASME, 66:99-105,

16. Demirbas MF (2006) Thermal energy storage and phase change materials: an overview. Energy Sources B Econ Plan Policy 1:85-95

17. Sharma T, Reddy ALM, Chandra TS, Ramaprabhu S (2008) Development of carbon nano- tubes and nanofluids based microbial fuel cell. Int J Hydrog Energy 33:6749-6754

18. You SM, Kim JH, Kim KH (2003) Effect of nanoparticles on critical heat flux of water in pool boiling heat transfer. Appl Phys Lett 108:3374-3376

19. Buongiorno J, Hu LW, Hannick R, Truong B, Forrest E (2008) Nanofluids for enhanced economics and safety of nuclear reactors: an evaluation of the potential features, issues, and research gaps. Nucl Technol 162:80-91

20. Kulkarni DP, Das DK, Vajjha RS (2009) Application of nanofluids in heating buildings and reducing pollution. Appl Energy 86:2566-2573

21. Nelson JC, Banerjee D, Ponnappan R (2009) Flow loop experiments using polyalphaolefin nanofluids. J Thermophys Heat Transf 23:752-761

22. Sun X, Liu Z, Welsher K, Robinson JT, Goodwin A, Zaric S, Dai $H$ (2008) Nano-graphene oxide for cellular imaging and drug delivery. Nano Res 1:203-212

23. Zhou J, Wu Z, Zhang Z, Liu W, Liu Q, Xue Q (2000) Tribological behavior and lubricating mech- anism of Cu nanoparticles in oil. Tribol Lett 8:213-218

24. Otanicar TP, Phelan PE, Prasher RS, Rosengarten G, Taylor RA (2010) Nanofluid-based direct absorption solar collector. J Renew Sustain Energy 2:033102

25. Wang XQ, Mujumdar AS (2007) Heat transfer characteristics of nanofluids: a review. Int J Thermal Sci 46:1-19

26. Y.W. Pradeep T. Das S.K., Choi S. Nanofluids: science and technology. Wiley Interscience, New Jersey, 2007
27. Buongiorno J (2006) Convective transport in nanofluids. ASME J Heat Transfer 128:240-50

28. Bachok N, Ishak A, Pop I (2010) Boundary-layer flow of nanofluids over a moving surface in a flowing fluid. Int J Therm Sci 49(9):1663-1668

29. Rana P, Bhargava R (2011) Numerical study of heat transfer enhancement in mixed convection flow along a vertical plate with heat source/sink utilizing nanofluids. Commun. Nonlinear Sci. Numer. Simulat. 16:4318-4334

30. Grosan T, Pop I (2011) Axisymmetric mixed convection boundary layer flow past a vertical cylinder in a nanofluid. Int J Heat Mass Transf 54(15-16):3139-3145

31. Zaimi K, Ishak A, Pop I (2014) Boundary layer flow and heat transfer over a nonlinearly permeable stretching/shrinking sheet in a nanofluid. Sci Rep 4404:1-8

32. Pătrulescu FO, Groşan T, Pop I (2014) Mixed convection boundary layer flow from a vertical truncated cone in a nanofluid. Int J Num Methods Heat Fluid Flow 24(5):1175-1190

33. Xu X, Chen S (2017) Dual solutions of a boundary layer problem for MHD nanofluids through a permeable wedge with variable viscosity. Boundary Value Problems

34. Oztop HF, Abu-Nada E (2008) Numerical study of natural convection in partially heated rectangular enclosures filled with nanofluids. Int J Heat Fluid Flow 29:1326-1336

35. Jain MK (1984) Numerical Solution Of Differential Equations. Wiley, New Delhi

36. Lok YY, Amin I, N. and Pop. (2006) Unsteady mixed convection flow of a micropolar fluid near the stagnation point on a vertical surface. Int J Thermal Sci 45:1149-1157

37. Hassanien IA, Gorla RSR (1990) Combined forced and free convection in stagnation flows of micropolar fluids over vertical non-isothermal surfaces. Int J Engng Sci 28:783-792

38. Bellman R E, Kalaba R (1965) Quasi-linearization and nonlinear boundary value problems. Elsevier, New York

39. Abu-Nada E (2008) Application of nanofluids for heat transfer enhancement of separated flows encountered in a backward facing step. Int J Heat Fluid Flow 29(29):242-249

40. Kuznetsov AV, Nield DA (2006) Boundary layer treatment of forced convection over a wedge with an attached porous substrate. J Porous Media 9:683-694

41. Ayd1n O, Kaya A (2007) Mixed convection of a viscous dissipating fluid about a vertical flat plate. Appl Math Model 31:843-853

42. Chamkha AJ, Mujtaba M, Quadri A, Issa C (2003) Thermal radiation effects on MHD forced convection flow adjacent to a nonisothermal wedge in the presence of a heat source or sink. Heat Mass Transfer 39:305-312

Publisher's Note Springer Nature remains neutral with regard to jurisdictional claims in published maps and institutional affiliations. 